\title{
Gedeon Mészöly 1880—1960
}

Gedeon Mészöly wurde am 10. Juni 1880 geboren; seinen 80. Geburtstag erlebte er nicht mehr, denn nur wenige Tage vorher, am 29. Mai 1960, erlosch sein Leben. In ihm haben wir rinen scharfsimigen Forscher des Ungarischen und der finnisch-ngrischen Sprachen verloren. Mrszöly wirkte als Professor an der Szegeder Universität, war korrespondierendes Mitgrlied der Lngarischen Akademie der Wissenschaften und widmete sich mehr als fünfrig Jahre lang seiner Wissenschaft, die rr mit aufrichtiger Begeisterung liebte.

I) Hauptgebiete seiner sprachwissenschaftlichen Tätigkeit bildeten die ungarische historische Wort- und Satzlehre sowie dir Wortschatzforschuma. Bei seinen wissenschaftlichen Arbriten, die einen weiten geistigen Horizont verraten, benutzto Mŕszöly in sachverständiger Weise auch die neuesten Ergebnisse der Ethnographie, der Kulturgeschichte und der Literaturgeschichte, wodurch wiederum auch diese Wissenschaften zahlreiche neue Impulse erhielten. Auch den Prozessen, die sich in der ungarischen Sprache selbst vollzogen hatten, walt seine Aufmerksamkeit.

In riner Reihr von interesiantr'n Ntudien beschäftionte er sich mit den urzeitlichen finnisch-ngrischen wirtschaftlichen, gesellschaftlichen und kulturellen Verhältnissen. Er untersucht" Fragen der Sammelwirtschaft, des urzeitlichen Fischfangs, der Jigd, des Ackerbaus, der Tierzucht, doch zeigte er sich auch als gründlicher Kenner der alten Glaubenswelt und der Volksdichtung (vgl. Mióta lovasnép a magyar? [Seit wann sind die [ngarn ein Reitervolk?]. Népünk és nyelvünk, 1929; Nem lovas nép volt-e az ugor-kori magyar? [Waren die Ungarn in der ngrischen Perinde kein Reitervolk?]. Ethn. 1930 41: 60-61; Az lưorkori vadászéla magyar szókincsbeli emlékei [Anden- 
ken an das Jägerleben der ugrischen Periode im ungarischen Wortschatz|. Ethn. 1951 62:277: Az ngorkori sámánosság magyar szókincsbeli emlékei [Andenken an das Schamanentum der uqr. Periode im ungar. Wortschatz|. Magyar Nyelr 1952 48: 46--6il usw.)

Ausser den genannten sind anch zahlreiche andere Arbeiten ron Mészöly immer wieder von Beobachtungen und Anmerkungen durchzogen, die er auf Grund der eingehenden Kenntnis der Forschungsprobleme und -resultate der finnisch-ugrischen Sprachen anstellen konnte. Fragen der ungarischen Sprache behandelte er nie isoliert, sondern als Teile eines grösseren Systems, wif sio einzuordnen sind in das System der finnischugrischen sprachen, wie die Entsprechungen innerhalb dor cinzelnen fiu. Sprachen dazu aussehen, wobei die Überprüfung vom ungarischen und finnisch-ugrischen Standpunkt zu einer organischen Gesamtheit verschmilzt. Auf diese Weise entstanden derart vorzügliche Untersuchungen wie "A Halotti Beszíd tárgyas elbeszélô múlt alakjai magyar és finnugor szempontbób (I)ie Formen der erzählenden Vergangenheit in der obj. Konjugation in dre Leichenrede vom ungar. und fin. Standpunkt aus; Bp. 1931), worin er ausgehend ron dem im Titel genannten Problem die Unhaltbarkeit jener Erklärung darlegt, wonach die objektive Konjugation aus der possessiven Flexion entstanden sei. Seiner Meinung nach kamen beide gleichzeitig zustande. Hier könnten wir auch die Studie erwähnen, die Mészöly über den Ursprungr des Suffixes -ral, -rel schrieb (Der zemeinsame Ursprung der Instrum.-komit.-suffixe ung. -val, -rel, wogr. -l und ost.j. -at. FUF 1933 21: 56-73).

In mehreren Artikeln kam rer in Verbindung mit einem 'Teilproblem zu wichtigen allgemeinen prinzipiellen Resultaten. Su schreibt er in einem seiner Aufsätze: "Es ist nicht richtig ..., wenn wir in unseren sprachgeschichtlichen, sprachvergleichenden Untersuchungen eine unüberschreitbare Grenze ziehen zwischen den Suffixen und den Bildungssilben, zwischen den bestimmenden und den nominativischen Formen" ( $\mathrm{N} y \mathrm{~K}$. 1910-11 XI, 327). Beachtenswert auch vom standpunkt der allgemeinen Finnougristik ist der hervorragende Aufsatz über die Herkunft des Suffixes -ik in dej Ingarischen Konjugation 
und den Ursprung der passivischen Bildung und Konstruktion. Nach ihm entwickelte sich die passivische Form nach der Trennung von den übrigen finnisch-ugrischen sprachen im Ungarischen aus der objektiven Konjugation des Aktivs (s. \yK. 1941-43 LI, 1-13). Wenn or die Wörter finnischugrischer und ugrischer Herkunft im Ungrarischen untersucht, dann wird gleichzeitig auch die Zeitperiode, die Gesellschaft und das Volk lebendig, welches dieses Wort benutzte, wo dieses Wort lebte. Gerade deshalb sind seine Artikel oft so anschalulich und lesen sich leicht.

Am liebsten beschäftigte er sich mit der Erforschung der ältesten ungarischen Sprachdenkmäler. In Verbindung mit der Untersuchung der Leichenrede und der altungarischen Marienklage entwickelte er eine neue Methode -- die sog. stilgeschichtliche Methode --, die auch von internationalem Interesse sein dürfte ( $\mathrm{A} z \mathrm{O}$-magyar Mária-siralom nyelvtörténeti és stílustörténeti magyarázata [Sprach- und stilgeschichtliche Auslegung der altungarischen Marienklage]. Kolozsvár, 1944; Nyelvtörténeti fejtegetések a Halotti Beszéd alapján [Sprachgeschichtliche Ausführungen auf Grund der Leichenrede]. Szeged, 1942; A Halotti Beszéd hangtörténeti és alaktani sajátságai [Die sprachgeschichtlichen und morphologischen Eigenheiten der Leichenredel. Szeged, 1926). Ein zusammenfassendes Bild der Ergebnisse und Methoden von Mészöly in der Erforschung der ältesten ungarischen Sprachdenkmäler wibt uns sein Buch Ómagyar szövegek nyelvtörténeti magyarázatokkal (Altungarische Texte mit sprachgeschichtlichen Erklärungen). Bp. 1956.

Nicht nur vom Resultat, sondern auch von der Methode he' verdienen seine Etymologien Beachtung (vgl. A láp szó eredete és rokonsága [Herkunft und Verwandtschaft des Wortes láp 'Moor, Sumpf']. SzegFüz. III, 87; A kidei Hintó-mező novének és a hinár szónak eredete [Der Ursprung des Namens Ilintó-mezố und des Wortes hinárl. Nép és Nyelv I, 225).

Das ganze Lebenswerk von Mészöly zeugt von einem Forscher, der einen weiten Gesichtskreis besass, der die sprachlichen Erscheinungen im organischen Ganzen, in ihrem untrennbaren Zusammenhang zu sehen vermochte. Seine Werke verdienen 
nicht nur wegen ihrer letzten Folgerungen Beachtung, sondern auch wegen der Methoden und des lebendigen Vortrags. Vielleicht kann die eine oder die andere Auffassung heute schon nicht mehr gelten, überzeugt sind wir jedoch davon, dass die sprachwissenschaftliche Forschung in der Zukunft noch zahlreiche Einfälle und $\dot{\mathrm{C}}$ berlegungen von Mészöly bestätigen wird. Wie das im Einzelnen auch geschehen wird, - bereits jetzt können wil feststellen, dass seine Aufsätze jedenfalls zum Nachdenken anregten, dass sif für den Leser ein Erlebnis bedeuteten und weiterhin bedenten. Deshalb bleibt er selbst in unserem Gedächtnis, der hervorragende Forscher, und deshalb bleiben seine Gedanken in unserem Gedächtuis.

ISTVÁx NYIRKOS 